\title{
Enterprise Information Systems and Technologies in Czech Companies from the Perspective of Trends in Industry 4.0
}

\author{
Josef Basl \\ University of Economics, Prague, Czech Republic \\ baslevse.cz
}

\begin{abstract}
The paper deals with aspects of ICT innovation based on the development of the internet of things in industrial companies. The article presents the main results of a pilot survey carried out in a number of Czech companies. They show the current understanding of Industry 4.0 principles and the penetration these trends in companies, including the penetration level of the main IT trends and integration role of enterprise information systems application in Industry 4.0.
\end{abstract}

Keywords: Enterprise information system, internet of things, industry 4.0, innovation, information and communication technology, cyber physical system

\section{Introduction}

Long-term forecasts and trends of global development show that information and communication technology will continue to play a leading role among innovation technologies. Trends such as big data and cloud computing are very important today, but it seems that they will remain very important over the next 10-15 years. For example, the document Global trends 2030 [7] emphasizes ICT as one of four key technological areas:

- Information and communication technology

- Technologies pertaining to the security of vital resources (food, water, and energy needs)

- New health technologies

- New manufacturing and automation technologies.

Manufacturing and automation technologies are crucial for the deployment of ICT and at the same time they also represent one of the key segments of the portfolio of the Czech economy with a strong influence on the Czech labour market [2]. The importance of ICT in the future is also emphasized in the survey done by the OECD [14] for example.

adfa, p. 1, 2011.

(c) Springer-Verlag Berlin Heidelberg 2011 


\section{Theoretical background}

There is no doubt that ICT play a key role in the development of the whole of society. ICT will be shaping the global economy, social, and military developments as well as the world community's actions pertaining to the environment by 2030 . Information technology will provide global access and pervasive services; social media and cybersecurity will be large new markets. Among the TOP 10 strategic technology trends according to the Gartner Group are [6]:

- $\quad$ The digital mesh
○ The device mesh
- Ambient user experience
- 3D printing machines

- Smart machines

○ Information of everything

- Advanced machine learning

- Autonomous agents and things

- $\quad$ The new IT reality
- Adaptive security architecture
- Mesh app and service architecture
- IoT architecture and platforms.

Advanced system architecture and virtual reality are examples of symptoms of the new important wave of changes. The time when it was trendy to talk about Web 2.0 or Enterprise 2.0 is partly behind us. At that time Enterprise 2.0 was dedicated to the use of emergent social software platforms within companies, or between companies and their partners or customers. The tools and services that employ Web 2.0 techniques such as tagging, ratings, networking, user commenting and discussion, open creation and editing policies started to be used at that time. [17].

But the current ICT trends do not only emphasize the social networking role of the internet. The internet is now also a platform for communication among machines and products. The internet offers a complete solution that goes beyond the potential and possibilities of traditional manufacturing industries.

All these changes are very significant and this new wave of changes is called the new, fourth industrial revolution. This revolution has started changes and movements that have never been experienced in society before.

To better understand the term 'fourth industrial revolution', the main principles of the previous three industrial revolutions should be remembered. The first industrial revolution was based on steam power and mechanization in industry. The second revolution was caused by electricity and mass production and connected with 'hard automation'. The third industrial revolution was based on computers and it was connected with 'flexible automation'. Finally, the current fourth revolution is also based on ICT but is associated with 'cyber physical systems'.

Fields such as automation, robots or digitalization of everything are important, and again the internet plays a key role - in the form of the internet of things (IoT) or ra- 
ther the internet of everything [5, 10]. This is the reason why we sometimes call the changes of Industry 4.0, 'factory 4.0' [9] or 'smart factory' [19]. This designation is a continuation of the term 'digital factory' which has been used in previous years.

The basic principles of Industry 4.0 are therefore the connection of machines, work pieces and systems, and businesses are creating intelligent networks along the entire value chain that can control each other autonomously.

Industry 4.0 is a way to improve production processes, to increase the productivity for batch size equal to 1 , to reflect individual demands and short term wishes. It helps to reduce lead time and time to market. It helps to reduce product development time and ad-hoc networking within cyber-physical systems. It helps transparency in real time, to make faster and more flexible decision making, to archive global optimization in development and production.

Examples for Industry 4.0 could be machines which can predict failures and trigger maintenance processes autonomously, or self-organized logistics which react to unexpected changes in production. Cyber-Physical Systems (CPS) is integrations of computation and physical processes [12,20].

Industry 4.0 means making important efforts not only at a technological but also at a national level. A good example has been set by the German government. The German Federal Ministry for Education and Research currently offers 183 different documents related to this topic. For example, there is a project of the future, "Assembly 4.0' which was presented with the project of the month award in 2016. Industry 4.0 was also proposed and adopted as a part of the 'High-Tech Strategy 2020 Action Plan' of the German government (Recommendations, 2013). The general expectation is a growth of Industry 4.0 in Germany until 2020 by about $1.7 \%$ each year - mainly in chemistry, manufacturing, ICT and farming.

Similar steps have been taken in other industrially developed countries like the USA (in the 'Industrial Internet' document [9] and China (in the 'Internet+' document [19] and in the ambitious plan 'Made in China 2025' [11]. The Chinese government declares here that the country is aiming at Industry 4.0 implementation.

It is very important to note that the Czech government also strongly supports the Industry 4.0 trends in the document 'The national strategy Industry 4.0' published in September 2015 [13]. It was prepared and guaranteed by the Czech Ministry for Industry and Trade. Not only technological trends are elaborated here, but the changes in the labor market are highlighted as well.

\section{Methodology - Formulation of the Aim and Research Questions}

This paper deals with a survey of the penetration of Industry 4.0 principles in Czech companies. The important questions concern the role of the selected IT trends and enterprise information system software applications within the Industry 4.0 framework now and in the near future (between 2 and 5 years). The other questions ask about the preparation of Czech companies for this new trend. 
The motivation for this survey was not only the current technological trends but the published manufacturing studies oriented towards Industry 4.0 penetration - on the global level [8] and on the national level in Germany [1,3,15].

The first of these surveys was the most significant. It was done by Infosys - a leader in consulting, technology, outsourcing and next-generation services and by the Institute for Industrial Management at the University of Aachen in Germany. The survey analyzed more than 400 companies in industrially highly developed countries - China, France, Germany, the United Kingdom and the United States. It shows the level of maturity of Industry 4.0 and the key findings of this study are as follows [8]:

- $\quad 85 \%$ of manufacturing companies globally are aware of the potential of technologies for increasing asset efficiency

- However, only $15 \%$ of enterprises surveyed have so far implemented dedicated strategies to this end by analyzing data from their machines

- The research revealed that the largest improvements planned over the next five years are in the areas of information interoperability, data standardization and advanced analytics

- It is interesting that one fifth of companies believe that by 2020 will achieve anything beyond recognizing the potential of the Industry 4.0 concept.

The results of the survey declare that from all the five analyzed countries (China, France, Germany, the UK and the US); China is the leading innovator and has the highest percentage of early adopters (57\%). Germany is in fourth place with only $21 \%$ of early adopters. The German attitude and its wide support of Industry 4.0 is a big inspiration for the Czech economy and companies. There are many German investors and owners of companies in the Czech Republic and there is also close business cooperation between both countries, with a large volume of mutual exports.

Another reason for the survey described in this paper is an effort to obtain a more detailed view of the current ICT trends that are somehow connected with ICT such as mobile devices, clouds and big data on the one hand and ERP, MES, BI and APS applications on the other. Last but not least, topics such as robots, smart logistics and flexible production planning were also observed.

The further research question in this survey examines whether the strategies for Industry 4.0 are being implemented at the proper level in Czech companies, in a way comparable with the situation in Germany (as there is a high level of integration of companies from both countries).

The main research questions in this survey are as follows:

1) Are the main ICT trends (like cloud computing, big data and internet of things) being applied in the current development of companies and is growth of their penetration expected over the next 5 years?

2) Do ERP systems play a main role as an integrate application software?

3) Are the main trends of Industry 4.0 (such as robots or adaptive maintenance) being applied in the current development of companies and is

4) Do Czech companies already have a strategy for Industry 4.0? 


\section{Sample Description and Data Collection}

To be able to answer the research questions, a special questionnaire form was created which was made available for the companies on the website. Data collection was carried out by completing the web form in June/July 2016.

A set of 169 companies was addressed by the survey. 24 companies answered, meaning that the survey had a $14.7 \%$ response rate. It is important that the sample of companies reflects well the profile of the whole Czech economy, because the majority of firms belong to the automotive industry (29\%) and mechanical engineering (25\%). The Czech Republic is, by the way, the most developed industrial EU country because its share of GDP from industry is $47.3 \%$ (Germany has only $40.2 \%$ ).

The companies that participated in the survey were mostly large companies with more than 250 employees $(66.7 \%)$ and middle sized companies $(25 \%)$. There was also balanced ownership of domestic investors (58.3\%) and foreign investors and owners $(41.7 \%)$. The importance for the validity of the data was the fact that it was mostly the directors or company owners (33.3\%) and top managers $(41.7 \%)$ who answered the questions in the form. It is interesting that only $4.2 \%$ of IT managers answered the questions.

There is one more aspect that characterizes the survey. The majority of companies that answered and participated in the survey declared that they have dealt with Industry 4.0 for either more than one year $(41.7 \%)$ or are dealing with it right now $(20.8 \%)$. Only one fifth of the companies $(20.8 \%)$ say that they know about this new trend but they do not want to implement it. On the other hand, only $8.3 \%$ of companies declared that they have not heard of Industry 4.0 so far.

Finally, there is one more interesting fact revealed by the survey. Those who answered the questions spent roughly one hour filling it in. This confirms the importance of the role of Industry 4.0. The main results of the survey and the answers are described below.

\section{$5 \quad$ Research results}

The results from the survey as a whole reflect the trends in the application of ICT (such as cloud computing and big data), IT supported technological trends (e.g. robots, predictive maintenance, digital manufacturing and smart logistics) and usability and integration of the traditional enterprise information systems packages (like ERP, MES and CRM for example) in the Industry 4.0 trends and principles. 


\subsection{ICT trends penetration}

The first research question: Are the main IT trends applied (like cloud computing, big data, internet of things) in the current development of companies and is growth of its penetration expected over the next 5 years?

The results show that all the selected topics are already being applied today. Cloud computing mostly in first place, big data is second and the industrial internet of things is in third position.

It is interesting that demand and implementation of all these three trends is not predicted to grow in the next five years, although their penetration is the basis for this, and it is crucial.

\begin{tabular}{|l|c|c|c|}
\hline IT trends & Used now & $\begin{array}{l}\text { Planned to be used in } \\
\text { following 2 years }\end{array}$ & $\begin{array}{l}\text { Planned to be used } \\
\text { in following 5 years }\end{array}$ \\
\hline $\begin{array}{l}\text { Industrial Internet of } \\
\text { Things }\end{array}$ & $3(13.0 \%)$ & $3(13.0 \%)$ & $1(4.3 \%)$ \\
\hline Cloud computing & $7(30.4 \%)$ & $2(8.7 \%)$ & $4(17.4 \%)$ \\
\hline Big data & $5(21.7 \%)$ & $2(8.7 \%)$ & $4(17.4 \%)$ \\
\hline Mobile devices & $9(39.1 \%)$ & $5(21.7 \%)$ & $1(4.3 \%)$ \\
\hline $\begin{array}{l}\text { BYOD concept } \text { your own device) } \\
\text { young }\end{array}$ & $2(8.7 \%)$ & $1(4.3 \%)$ & $2(8.7 \%)$ \\
\hline Google glasses & $1(4.3 \%)$ & $2(8.7 \%)$ & $1(4.3 \%)$ \\
\hline Smart watches & $2(8.7 \%)$ & $1(4.3 \%)$ & $2(8.7 \%)$ \\
\hline $\begin{array}{l}\text { Open software architec- } \\
\text { ture }\end{array}$ & $1(4.3 \%)$ & $2(8.7 \%)$ & $1(4.3 \%)$ \\
\hline Open protocols & $1(4.3 \%)$ & $2(8.7 \%)$ & $1(4.3 \%)$ \\
\hline Open data models & & $2(8.7 \%)$ & 0 \\
\hline
\end{tabular}

The industrial internet of things is one of the key aspects of the whole new wave of changes known as the 4.0 industrial revolution. Therefore, it is interesting that enterprises want to know more information about it - nearly one half of them $(47.8 \%)$. The other two main trends (cloud computing and big data) are also topics which need to be further explained for nearly one third of the enterprises. 


\begin{tabular}{|l|c|}
\hline \multicolumn{1}{|c|}{ IT trends } & $\begin{array}{c}\text { We would like get more } \\
\text { information }\end{array}$ \\
\hline Industrial Internet of Things & $11(47.8 \%)$ \\
\hline Cloud computing & $6(26.1 \%)$ \\
\hline Big data & $7(30.4 \%)$ \\
\hline Mobile devices & $8(34.8 \%)$ \\
\hline BYOD concept (bring your own device) & $11(47.8 \%)$ \\
\hline Google glasses & $13(56.5 \%)$ \\
\hline Smart watches & $13(56.5 \%)$ \\
\hline Open software architecture & $11(47.8 \%)$ \\
\hline Open protocols & $13(56.5 \%)$ \\
\hline Open data models & $14(60.9 \%)$ \\
\hline
\end{tabular}

New trends like Google glass $(56.5 \%)$, smart watches $(56.5 \%)$ and open protocols $(56.5 \%)$ are the topics which companies would most like to have further explained.

\subsection{Enterprise information systems packages integration in the Industry 4.0 perspective}

The second research question: Do ERP systems play a main role as an integrate application software?

The results confirm the key role of ERP systems $(65.2 \%)$ in the integration of plans of companies during the preparation for Industry 4.0. The next most important package is MES application. 


\begin{tabular}{|l|c|l|}
\hline Enterprise information system application & Responses & Ratio \\
\hline ERP (Enterprise Resource Planning) & 15 & $65.2 \%$ \\
\hline MES (Manufacturing Execution System) & 10 & $43.5 \%$ \\
\hline APS (Advanced Planning and Scheduling) & 5 & $21.7 \%$ \\
\hline PLM (Product Lifecycle Management) & 6 & $26.1 \%$ \\
\hline WMS (Warehouse Management System) & 8 & $34.8 \%$ \\
\hline BI (Business Intelligence) & 7 & $30.4 \%$ \\
\hline BPM/BPMS (Business Process Management Suites) & 1 & $4.3 \%$ \\
\hline Other SW applications: & 4 & $17.4 \%$ \\
\hline
\end{tabular}

Other SW applications mentioned included: CRM, technomatix, NX, voice technology and paperless documentation.

\subsection{ICT based technologies penetration in the future of Industry 4.0}

The third research question: Are the main trends of Industry 4.0 (robots, adaptive maintenance) being applied in the current development of companies and is growth of its penetration expected over the next 5 years?

The three most important IT based technologies are - robots $(39.1 \%)$, digital factory $(30.4 \%)$ and predictive maintenance $(30.4 \%)$. The higher demand for the following 2 years is expected for predictive maintenance $(34.8 \%)$ and smart logistics $(26.1 \%)$. $3 \mathrm{D}$ printing is used extensively now and there are high expectations that it will be in use even in 5 years' time.

\begin{tabular}{|l|c|c|c|}
\hline IT based technologies & Used now & $\begin{array}{l}\text { Planned to be used in } \\
\text { following 2 years }\end{array}$ & $\begin{array}{c}\text { Planned to be used } \\
\text { in following 5 years }\end{array}$ \\
\hline Digital factory & $7(30.4 \%)$ & $4(17.4 \%)$ & $2(8.7 \%)$ \\
\hline Adaptive automation & $3(13.0 \%)$ & $4(17.4 \%)$ & $5(21.7 \%)$ \\
\hline Robots & $9(39.1 \%)$ & $3(13.0 \%)$ & $1(4.3 \%)$ \\
\hline Industrial 3D printing & $6(26.1 \%)$ & $4(17.4 \%)$ & $4(17.4 \%)$ \\
\hline Smart logistics & $4(17.4 \%)$ & $6(26.1 \%)$ & $3(13.0 \%)$ \\
\hline Predictive maintenance & $7(30.4 \%)$ & $8(34.8 \%)$ & 0 \\
\hline Cybernetic data security & $5(21.7 \%)$ & $4(17.4 \%)$ & 0 \\
\hline
\end{tabular}


The main topics for further education and requirements for additional awareness are "cybernetic data security (39.1\%) followed by adaptive automation (34.8\%), digital factory, predictive maintenance and industrial 3D printing (30.4\%).

\begin{tabular}{|l|c|}
\hline IT based technologies & $\begin{array}{l}\text { We would like get more in- } \\
\text { formation }\end{array}$ \\
\hline Digital factory & $7(30.4 \%)$ \\
\hline Adaptive automation & $8(34.8 \%)$ \\
\hline Robots & $5(21.7 \%)$ \\
\hline Industrial 3D printing & $7(30.4 \%)$ \\
\hline Smart logistics & $6(26.1 \%)$ \\
\hline Predictive maintenance & $7(30.4 \%)$ \\
\hline Cybernetic data security & $9(39.1 \%)$ \\
\hline
\end{tabular}

\subsection{Existence of an Industry 4.0 strategy}

The fourth research question is: Do Czech companies have a strategy for Industry 4.0 ?

A high percentage of Czech enterprises (39.1\%) do not currently have a strategy for Industry 4.0. Nearly the same percentage of enterprises is preparing such strategy $(30.4 \%)$. And finally, nearly $25 \%$, it means each fourth company, already has a strategy for Industry 4.0. This is very similar to the answers from firms in the global survey (by Infosys, 2015).

\begin{tabular}{|l|c|r|}
\hline \multicolumn{1}{|c|}{ Strategy for Industry 4.0 } & Responses & Ratio \\
\hline We do not have a strategy for Industry 4.0 & 9 & $39.1 \%$ \\
\hline $\begin{array}{l}\text { We do not have a strategy for Industry now but we are preparing } \\
4.0\end{array}$ & 7 & $30.4 \%$ \\
\hline $\begin{array}{l}\text { We have a strategy for Industry } 4.0 \text { and it is a part of business } \\
\text { strategy }\end{array}$ & 4 & $17.4 \%$ \\
\hline $\begin{array}{l}\text { We have a strategy for Industry } 4.0 \text { but it is not a part of business } \\
\text { strategy }\end{array}$ & 2 & $8.7 \%$ \\
\hline
\end{tabular}




\section{Conclusion}

Industry 4.0 seems to be a topic with a high potential, especially at a time when the digitalization of production and of life in general is increasing. The survey indicates many similarities between Industry 4.0 penetration in Czech companies and in leading developed countries.

The survey identified a big potential for further analyses and the obstacles preventing the wider application of Industry 4.0. The main reason for companies is that there is little awareness of the issues of Industry 4.0 (73.3\% declare this), and the effects on business are unclear $(40 \%)$. The high costs connected with implementing Industry 4.0 $(40 \%)$ are also cited as one of the obstacles.

The survey shows that companies perceive the level of penetration to be very low and they also feel that there are as yet no proper methodologies or road maps for implementing Industry 4.0. These aspects are again possible further areas for research.

Last but not least is the fact that it has a crucial influence on the labour market. It is expected that many jobs will be lost because of Industry 4.0. This fact is more important for the Czech Republic, which experienced the biggest growth of jobs after the crisis, especially in manufacturing (OECD, 2015). It will therefore be necessary to keep a balance within Industry 4.0 developments from both technological and social perspectives.

\section{References:}

1. Computer Sciences Corp: CSC - Studie Industrie 4.0: Ländervergleich Dach, 2015, http://assets1.csc.com/de/downloads/Ergebnisse_CSC-Studie_4.0.pdf. Accessed: 2016-0427

2. Doucek, P.: Human Capital in ICT - Competitivness ind Innovation Potential in ICT, In. IDIMT-.2011, Jindřichův Hradec, 7.09.2011 - 9.09.2011. Linz : Trauner Verlag universitat, 2012, p. 11-23. ISBN 978-3-85499-973-0.

3. Eisert, R. (2014b). Sind Mittelständler auf Industrie 4.0 vorbereitet?, $\mathrm{http} / / / \mathrm{www}$.wiwo.de/unternehmen/mittelstand/ innovation-readiness-index-sindmittelstaendler-auf-industrie-4-0-vorbereitet/10853686.html. Accessed: 2016-04-27

4. Factory 4.0? Lab where you will sit in front of PC http://zpravy.aktualne.cz/ekonomika/tovarna-40-laborator-ve-ktere-budete-sedet-upocitace-ukazuj/r 4e1ca8206cf611e58f1e002590604f2e/, Accessed: 2016-04-27

5. F. Tao, Y. Zuo, L. D. Xu, L. Zhang: IoT-Based intelligent perception and access of manufacturing resource toward cloud manufacturing, IEEE Transactions on Industrial Informatics , vol. 10, no. 2, pp. 1547-1557, 2014

6. Gartner - Top 10 Strategic Technology Trends for 2016, http://www.gartner.com/technology/research/top-10-technology-trends/, Accesed: 201604-27

7. Global Trends 2030: Alternative Worlds, National Intelligence Council, 2012, https://globaltrends2030.files.wordpress.com/2012/11/global-trends-2030november2012.pdf Accessed: 2016-04-27 
8. Industry 4.0 - The State of the Nations, INFOSYS, http://images.experienceinfosys.com/ Web/Infosys/\%7Bf0e3bb53-176a-4b5a-991b-0708c00fc0a9\%7D_Industry_4.0_-

_The_State_of_the_Nations_2015_-_Research_Report.pdf, Accessed: 2016-04-27

9. The Industrial Internet Consortium: A Global Nonprofit Partnership of Industry, Government and Academia, 2014, http://www.iiconsortium.org/about-us.htm. Accessed: 2016-0427

10. Jing. Q. , Vasilakos A. V., Wan J., J. Lu, D. Qiu, "Security of the Internet of Things: perspectives and challenges," Wireless Networks, vol. 20, no. 8, pp. 2481-2501, 2014

11. Kenedy, S.: Made in China 2025, Center for Staretegic and Internatinal Studies, 2015, http://csis.org/publication/made-china-2025, Accessed: 2016-04-27

12. Lee, E. A.: Cyber Physical Systems: Design Challenges, Technical Report No. UCB/EECS-2008-8, http://www.eecs.berkeley.edu/Pubs/TechRpts/2008/EECS-20088.html, Accessed: 2016-04-27

13. National Iniative - Industry 4.0, Ministery for Industry and Trade, September 2015, http://www.spcr.cz/images/priloha001-2.pdf, Accessed: 2016-04-27

14. OECD Science, Technology and Industry Scoreboard 2015, Innovation for Growth and Society,2016, http://www.oecd.org/science/oecd-science-technology-and-industryscoreboard-20725345.htm, Accessed: 2016-04-27

15. Perspektive Mittelstand: Industrie 4.0 macht Mittelstand zu schaffen, 2015, http://www.perspektive-mittelstand.de/Industrie-40-macht-Mittelstand-zu-

schaffen/managementwissen/6093.html., Accessed: 2016-04-27

16. Premier of the State Council of China and K. Q. Li, "Report on the work of the government," in Proceedings of the 3rd Session of the 12th National People's Congress, March 2015, Accessed: 2016-04-27.

17. Report: Accessed: Research and Markets: Enterprise 2.0: Is It Time for Your Organization to Make the Transition, 2008, http://search.proquest.com/docview/446162456?accountid=149652016-04-27, Accesed: 2016-04-27

18. Soliman, F., Youssef M. A.: Internet-based e-commerce and its impact on manufacturing and business operations, Industrial Management \& Data Systems, vol. 103, no. 8-9, pp. 546-552, 2003.

19. Wang S., Wan J., Li D., Zhang C.: Implementing Smart Factory of Industrie 4.0: An Outlook, International Journal of Distributed Sensor Networks, Volume 2016 (2016), Article ID 3159805, 10 pages, http://dx.doi.org/10.1155/2016/3159805

20. Wan J., Yan H., Liu Q., Zhou K., Lu R., Li D.: Enabling cyber-physical systems with machine-to-machine technologies, International Journal of Ad Hoc and Ubiquitous Computing, vol. 13, no. 3-4, pp. 187-196, 2013.

21. Xu X.: From cloud computing to cloud manufacturing, Robotics and Computer-Integrated Manufacturing, vol. 28, no. 1, pp. 75-86, 2012 